\title{
Factors Affecting Seed Germination and Establishment of an Efficient Germination Method in Sugar Pine (Pinus lambertiana Dougl.)
}

\author{
Xiuli Shen and Myeong-Je Cho \\ Innovative Genomics Institute, University of California, 2151 Berkeley Way, \\ Berkeley, CA 94704
}

Additional index words. embryo culture, in vitro propagation, seed dormancy, tissue culture

\begin{abstract}
Mature sugar pine (Pinus lambertiana Dougl.) trees produce large amounts of viable seeds but have seed dormancy. In this study, we used three sugar pine genotypes, $\mathbf{8 8 7 7}, 9306$, and 9375 , to test seed germination response. Seed germination from local sources varied greatly, and germination percentages were poor. There was a large variation in seed size and seed weight among the genotypes. Seeds of 9375 and 9306 were significantly larger and heavier (30.7 and $28.8 \mathrm{~g} / 100$ seeds, respectively) than 8877 (23.6 g/ 100 seeds). Three types of seeds - intact seeds, hulled seeds, and naked embryos-were examined for germination. Intact seeds failed to germinate due to the physical restraint and water impermeability of the seed. Chemical scarification with 5 м hydrochloric acid and 5 m sodium hydroxide did not soften the hard seedcoat and also failed to induce any germination of intact seeds. Hulled seeds resulted in an extremely low germination percentage $(\leq 5 \%)$ with abnormal seedling development even though the endosperm was water permeable. Germination of the hulled seeds was not increased by adding $1 \mathrm{mg} \cdot \mathrm{L}^{-1}$ gibberellic acid to the culture medium. Artificial opening of the hulled seeds created by longitudinal or horizontal cuts on the endosperm after removal of the seedcoat to avoid physical restraint and allow air exchange also failed to improve germination, indicating that inhibitors related to germination were present in the endosperm. However, naked embryos of all three genotypes germinated rapidly and uniformly with $70 \%$ to $95 \%$ germination percentage regardless of cold stratification treatment. Our data indicate that sugar pine seeds from the current source did not have physiological dormancy of embryos themselves, but dormancy was imposed by the seedcoat and endosperm. Using the naked embryos as donor explants, we have successfully established an efficient in vitro culture system. The protocol described here can be applied for the tissue culture and genetic transformation of sugar pine.
\end{abstract}

Sugar pine (Pinus lambertiana Dougl.), a gymnosperm belonging to the family of Pinaceae prized for its economic and ecological value, is one of the most valuable softwood forest plant species in the western United States. Native to the region from northern Oregon to Baja California, it is the largest species in the genus and is the tallest and most massive pine tree (Ahlstrom, 1992; Cermak, 1992; Kinloch and Scheuner, 1990; Maloney et al., 2011).

Sugar pine is the most susceptible to white pine blister rust (WPBR) caused by Cronartium ribicola. The disease is rated as one of

\footnotetext{
Received for publication 2 Nov. 2020. Accepted for publication 8 Dec. 2020.

Published online 15 February 2021.

We thank Richard S. Dodd and Angel Fernandez i Marti from the Department of Environmental Science at University of California-Berkeley for providing seeds used in this study. This work was funded by the Innovative Genomics Institute of the University of California-Berkeley.

M.-J.C. is the corresponding author. E-mail: mjcho1223@berkeley.edu.

This is an open access article distributed under the CC BY-NC-ND license (https://creativecommons. org/licenses/by-nc-nd/4.0/).
}

the worst pandemics in history, and its impact on the sugar pine natural population has been devastating (Devey et al., 1995; Ferrell and Scharpf, 1992). Traditional breeding efforts to create rust-resistant sugar pine by hybridizing sugar pine with rust-resistant white pine species have been hindered by long breeding cycles, the availability of rust-resistant species, incompatibility barriers among species, and poor hybrid seed production (Fernando et al., 2005). Recent advances in genetic engineering have provided an alternative opportunity to generate resistant sugar pine varieties in a greatly shortened time frame (Malabadi and Nataraja, 2017; Maleki et al., 2018; Marti and Dodd, 2018).

Because sugar pine tree does not sprout (Kinloch and Scheuner, 1990), it is very difficult to establish in vitro from vegetative parts of mother plants. Reproduction through seeds in vitro is the only option to explore. Seed propagation has several advantages for mass production in sugar pine. Sugar pine bears the longest cones of all conifers, so seeds are abundant (Cermak, 1992). Using seeds to initiate in vitro culture normally results in less contamination than using vegetative parts of plants. However, sugar pine seeds are difficult to germinate and are characterized by irregular germination from diverse sources (Baron, 1978; Krugman, 1966).

Seed germination is a complex process governed by internal and external factors. Among factors affecting germination, the state of the seeds themselves is the most important. Some seeds might be dormant while others are not (Bewley, 1997; Nelson, 2015). It is commonly believed that tree seeds possess some types of dormancy, physically or physiologically (or both). Studies on the dormancy and germination in Pinus species were reported, and different factors, alone or in combination, were attributed to dormancy in different Pinus species. Researchers found that seedcoat played an important role in seed dormancy, and germination could be improved by removal of seedcoat (Barnett, 1972, 1976), whereas others discovered that inhibitors existed in seedcoat and endosperm were related to seed dormancy (Li et al., 1989; Xin, 2008). Studies noted that dormancy was caused by underdeveloped embryos, and seedcoat removal alone could not overcome dormancy; thus, special treatment such as cold stratification was needed for germination (Carpita et al., 1983; Dong et al., 2002; Stone, 1957).

Among treatments to break dormancy and thus improve germination, cold stratification is the most widely used. Various studies have shown its stimulating effect on seed germination in different Pinus species (Barnett, 1997; Cooke et al., 2002; Donald, 1987; Ghildiyal et al., 2009; McLemore and Czabator, 1961). On the other hand, some studies found that stratification did not affect seed germination (Nelson, 2015; Tanaka, 1984). Stratification temperature and duration exerted a significant effect on germination (Allen 1960; Malik and Shamet, 2008; Malik et al., 2008). The inductive effect of stratification was shown to vary among seed sources (Schubert, 1955; Skordilis and Thanos, 1995).

Another commonly used treatment to promote seed germination is the exogenous application of gibberellic acid $\left(\mathrm{GA}_{3}\right)$. It is well known that the plant hormone $\mathrm{GA}_{3}$ has a function in overcoming dormancy and stimulates seed germination in some species (Kucera et al., 2005). Studies with certain Pinus species supported this claim (Kumar et al., 2014; Lavania et al., 2006; Zhao and Jiang, 2014). Chemical scarification is often used to soften hard seedcoat or to rupture seedcoat to increase germination (Pitel and Wang, 1989).

Few studies have been done in sugar pine on seed dormancy and germination. In our preliminary experiments, no germination could be obtained with intact seeds. In the present study, we investigated factors governing dormancy and germination in sugar pine. Ultimately, the objective of this study was to develop a reliable and rapid in vitro germination protocol in sugar pine. To achieve this goal, we sought to 1) examine 
seed morphology and structure of sugar pine varieties; 2) determine germinability of three types of seeds (intact seeds, hulled seeds, and naked embryos); 3 ) investigate the effects of tissues surrounding embryos on seed dormancy and germination; and 4) determine the effectiveness of cold stratification, chemical scarification, $\mathrm{GA}_{3}$ treatment, and artificial opening on seed germination. The results of this study can be applied to establish a tissue culture and genetic transformation protocol for sugar pine.

\section{Materials and Methods}

Seed source. Three genotypes of mature sugar pine seeds, 8877 (source \#322.40), 9306 (source \#741.40), and 9375 (source \#534.65), were obtained from the LA Moran Reforestation Center located in Davis of California (Fig. 1A). Half of the seeds were stored at a room temperature of $\approx 22{ }^{\circ} \mathrm{C}$. The remaining half were put in a small box and kept at $4{ }^{\circ} \mathrm{C}$ in a cold room for 3 months for cold stratification.
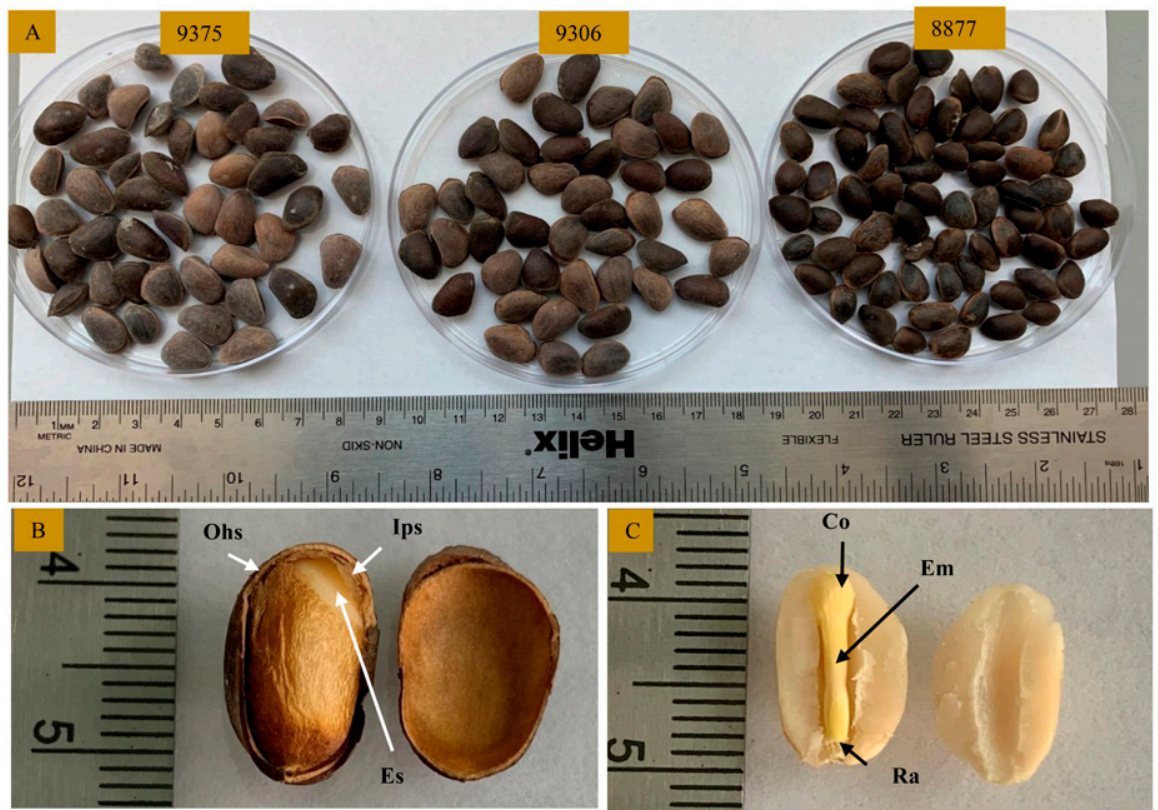

Fig. 1. Sugar pine seed morphology and structure. (A) Intact seeds. From left to right: genotypes 9357, 9306, and 8877. (B) Seed structure: outer hard seedcoat (Ohs), inner papery seedcoat (Ips), and endosperm (Es). (C) Seed structure: longitudinal cut endosperm and embryo. Em = embryo; Co = cotyledon; $\mathrm{Ra}=$ radicle

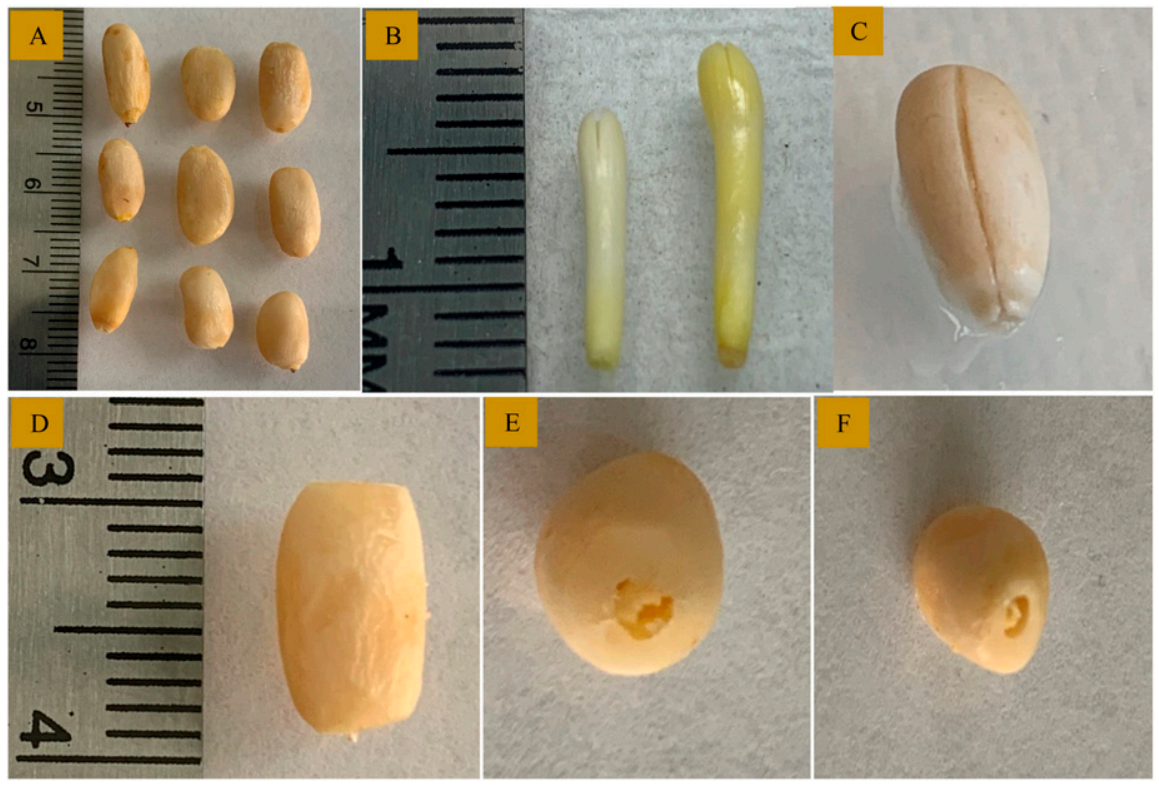

Fig. 2. Hulled seeds, naked embryos, and hulled seeds with treatments of sugar pine. (A) Hulled seeds were prepared for sterilization and germination. (B) Naked embryos showed variation in size and color. (C) A hulled seed was cut longitudinally. (D) A hulled seed was cut horizontally at both ends. (E) Top view of horizontally cut endosperm showing the cotyledon end. (F) Bottom view of horizontally cut endosperm showing the radicle end.

Seed structure and morphological characteristics. The weights of three samples of 100 randomly selected seeds from each variety were measured. Seed structure and morphology were examined by sequential removal of tissues of seed components. On the basis of the examination of seed structure, three types of seeds were created with sequential removal of tissues surrounding the embryo: 1) intact seeds (including outer hard seedcoat, inner papery seedcoat, endosperm, and embryo) (Fig. 1A); 2) hulled seeds (containing endosperm and embryo without seedcoat) (Fig. 2A); 3) naked embryos (embryo only without seedcoat and endosperm) (Fig. 2B). These seeds were germinated with different treatments to investigate the effects of various seed components on germination.

General sterilization procedure. In preliminary experiments, we experienced high contamination rates when culturing seeds in vitro. The following sterilization procedure worked best for reducing the contamination rate.

Intact seeds: intact seeds were placed under running water for $4 \mathrm{~h}$, then immersed in $30 \%$ germicidal ultra bleach (Pure Bright, $8.25 \%$ sodium hypochlorite) with the addition of 2 drops of Tween-20 for $1 \mathrm{~h}$. Sterilized seeds were rinsed three times, $5 \mathrm{~min}$ each, with sterile water, then soaked in sterile water for $24 \mathrm{~h}$.

Hulled seeds: intact seeds were carefully cracked with a pair of pliers. The outer hard seedcoat was removed, then the inner papery seedcoat was also removed with pointed tweezers. Hulled seeds were immersed in $30 \%$ germicidal ultra bleach for $20 \mathrm{~min}$. Sterilized hulled seeds were rinsed three times, $5 \mathrm{~min}$ each, with sterile water, then soaked in sterile water for $24 \mathrm{~h}$.

Naked embryos: the sterilization procedure was the same as for hulled seeds. After $24 \mathrm{~h}$ soaking in sterile water, the endosperm was longitudinally cut open and the embryo was aseptically isolated from the endosperm under an optical stereomicroscope (Leica KL 300 LED). Care was taken not to cause any injury to the embryo.

General culture media and conditions. Seed germination medium consisted of Murashige and Skoog (MS) salts and vitamin (Murashige and Skoog, 1962) with the addition of $20 \mathrm{~g} \cdot \mathrm{L}^{-1}$ sucrose. The medium was adjusted to $\mathrm{pH} 5.8$ with $1 \mathrm{~m} \mathrm{KOH}$, then supplemented with $6 \mathrm{~g} \cdot \mathrm{L}^{-1}$ TC agar (PhytoTechnology Laboratories, Shawnee Mission, KS) and autoclaved for $30 \mathrm{~min}$. Seeds were cultured in $10 \times 25 \mathrm{~mm}$ petri dishes (Thermo Fisher Scientific, Waltham, MA) containing $20 \mathrm{~mL}$ of medium. There were four seeds per petri dish and 10 replicate dishes per treatment. Cultures were maintained in a Percival scientific growth chamber (Geneva Scientific, Fontana, WI) at a temperature of $26{ }^{\circ} \mathrm{C}$ with a $16 / 8$-h light/dark photoperiod at $60 \mu \mathrm{mol} \cdot \mathrm{m}^{-2} \cdot \mathrm{s}^{-1}$ provided by cool white fluorescent lamps.

Cold stratification. The germinability of the aforementioned three types of seeds, both 
stratified and nonstratified (as the control), were investigated among the three genotypes. Seeds were sterilized and cultured on seed germination medium.

Water permeability test. Methylene blue was used to test whether protective layers of seedcoat and endosperm were permeable, and thus elucidate whether access to water was a factor limiting seed germination. Intact seeds, hulled seeds, and embryos were immersed in $1 \%$ methylene blue aqueous solution and sterile distilled water (as the control) for up to $7 \mathrm{~d}$. The seeds were washed, dried, longitudinally cut open, and examined for staining with an optical stereo microscope on a daily basis.

Intact seed treatment with chemical scarification. Chemical scarification was applied to intact seeds to examine whether seedcoats could be softened and germination could be improved. Intact seeds were placed under running water for $4 \mathrm{~h}$, then immersed in $5 \mathrm{~m}$ sodium hydroxide $(\mathrm{NaOH})$ and $5 \mathrm{~m}$ hydrochloric acid $(\mathrm{HCl})$ for $4 \mathrm{~h}$, respectively. Seeds were rinsed three times, 5 min each, with sterile water, then soaked in sterile water for $24 \mathrm{~h}$. Nonscarified seeds were used as the control. These seeds were cultured on seed germination medium.

Hulled seed treatment with $G A_{3}$. The effect of $\mathrm{GA}_{3}$ on seed germination was tested using cold-stratified seeds of the three genotypes. Hulled seeds were sterilized and cultured on seed germination medium supplemented with $1 \mathrm{mg} \cdot \mathrm{L}^{-1} \mathrm{GA}_{3}$. Filtersterilized $\mathrm{GA}_{3}$ was added to the aforementioned seed germination medium after the autoclaved medium was cooled down to 40 to $50{ }^{\circ} \mathrm{C}$. The medium without $\mathrm{GA}_{3}$ was used as the control.

Hulled seed treatment-longitudinal and horizontal cuts. Cold-stratified seeds of the three genotypes were tested. An artificial opening was made on endosperm to determine whether endosperm played a role in limiting seed germination by creating a me-

Table 1. Average hundred seed weight of three sugar pine genotypes.

\begin{tabular}{lc}
\hline Variety & $\mathrm{Wt} / 100$ seeds $(\mathrm{g})^{2}$ \\
\hline 9375 & $30.7 \pm 0.7 \mathrm{a}$ \\
9306 & $28.8 \pm 0.4 \mathrm{a}$ \\
8877 & $23.6 \pm 0.2 \mathrm{~b}$ \\
\hline
\end{tabular}

${ }^{\mathrm{z}}$ A total of 900 seeds were measured with three replicates and 100 seeds per replicate for each variety. Means followed by the different letters in each column are significantly different at the 0.05 level. chanical barrier, preventing air exchange and water imbibition. After sterilization of hulled seeds, a longitudinal cut (Fig. 2C) or horizontal cuts at both ends (Fig. 2D-F) were made to create artificial openings on the endosperm, with care not to cause any injury to the embryos inside. These seeds were cultured on germination medium. Hulled seeds with no cuts were used as the control.

Data collection and statistical analysis. The number of germinated seeds was recorded for embryos after 4 weeks in culture and for intact seeds and hulled seeds after 12 weeks in culture. The germination percentage was calculated as the number of germinated seeds out of the total number of cultured seeds. All experiments were established in a completely randomized design. Data were subjected to analysis of variance using SAS (SAS Institute Inc., Cary, NC). Mean separation was achieved by Tukey's honestly significant difference test at the $95 \%$ level.

\section{Results}

Seed structure and morphological characteristics. Sugar pine seeds are large, having a size of $\approx 1 \mathrm{~cm}$ in length and $5 \mathrm{~mm}$ in width. Seed coat color is brown to nearly black. Among the three genotypes examined in this study, seeds of 9306 and 9375 were larger than the seeds of 8877 (Fig. 1A). The average weight of 100 seeds was $30.7 \mathrm{~g}$ for 9375, $28.8 \mathrm{~g}$ for 9306 , and $23.6 \mathrm{~g}$ for 8877 . There was no significant difference in the average weight of 100 seeds between 9375 and 9306; however, both were significantly heavier than 8877 (Table 1).

Sugar pine seed consists of four distinct components: 1) a dark-brown, hard outer seedcoat (Fig. 1B); 2) a brown, papery inner seedcoat (Fig. 1B); 3) a firm, white endosperm (Fig. 1C); and 4) a white to light yellow, soft embryo (Fig. 1C).

Cold stratification-germination of the three seed types. Among the three types of seeds tested for germination, intact seeds, both stratified and nonstratified, did not show germination after 12 weeks in culture (Table 2). Extremely low germination $(\leq 5 \%)$ was obtained with hulled seeds with abnormal seedling development. Cold stratification did not significantly increase the germination percentage of hulled seeds. Naked embryos germinated rapidly and uniformly (Table 2). Germination of $70 \%$ to $95 \%$ was noted among the three varieties. Cold stratification did not improve germina- tion of embryos within genotype. The best germination of $95 \%$ was obtained with coldstratified embryos of 9306; however, it was not significantly different from 9306 (nonstratified), 9375 (cold stratified), and 8877 (both stratified and nonstratified). Significantly lower germination of $70 \%$ was observed with nonstratified embryos of 9375 (Table 2).

Sugar pine embryo is large and has a size of $\approx 8 \mathrm{~mm}$ in length. It is white to light yellow in color and composed of radicle, embryonic axis, and cotyledons (fascicle of needles) (Figs. 1C and 3A). Naked embryos germinated rapidly. The visible stages of germination consistently occurred. After $\approx 3 \mathrm{~d}$ in culture, the emergence of radicles, elongation of embryonic axes, and expansion of cotyledons were noted (Fig. 3B). They turned green after $\approx 7 \mathrm{~d}$ in culture (Fig. 3C). A complete, fully developed seedlings could be obtained in $\approx 4$ weeks (Fig. 3D). Shoot multiplication occurred in the following weeks (Fig. 3E).

Water permeability test. Permeability of seed covering layers, endosperm, and embryo were assessed by immersing intact seeds, hulled seeds, and naked embryos in methylene blue for up to $7 \mathrm{~d}$. Staining was examined daily in longitudinally cut seeds. Seeds of sugar pine were found to have a waterimpermeable seedcoat because no staining in endosperm and embryo could be observed in seeds soaked in methylene blue for up to $7 \mathrm{~d}$ (Fig. 4B). Endosperm was stained partially after $1 \mathrm{~d}$ (Fig. 4C) and completely stained after $2 \mathrm{~d}$ soaking in methylene blue (Fig. 4D). These results suggested that endosperm could absorb water. Naked embryos could be stained completely after only $1 \mathrm{~h}$ of soaking (Fig. 4E and F).

Intact seeds treatment with chemical scarification. Seed coats could not be softened or ruptured by soaking in strong acid $(5 \mathrm{M} \mathrm{HCl})$ (Fig. $5 \mathrm{~A})$ or strong alkaline $(5 \mathrm{M}$ $\mathrm{NaOH})$ (Fig. 5B) for $4 \mathrm{~h}$. Chemical-scarified intact seeds did not germinate even after 12 weeks in culture.

Hulled seed treatment with $G A_{3} . \mathrm{GA}_{3}$ treatment did not affect germination of hulled seeds. No significant increase in germination was observed in hulled seeds cultured on germination medium supplemented with 1 $\mathrm{mg} \cdot \mathrm{L}^{-1} \mathrm{GA}_{3}$ after 12 weeks in culture (Table 3).

Hulled seed treatment with longitudinal or horizontal cut. Longitudinal or horizontal cuts were made on the endosperm to create artificial openings with a purpose to remove

Table 2. Effect of stratification on in vitro germination of three types of seeds of three sugar pine genotypes.

\begin{tabular}{|c|c|c|c|c|}
\hline \multirow[b]{2}{*}{ Variety } & \multirow[b]{2}{*}{ Temperature $\left({ }^{\circ} \mathrm{C}\right)$} & \multicolumn{3}{|c|}{ Germination $(\%)^{\mathrm{z}}$} \\
\hline & & Intact seeds & Hulled seeds & $\overline{\text { Naked embryos }}$ \\
\hline 9375 & 4 & 0 & $5.0 \pm 3.3 \mathrm{a}$ & $85.0 \pm 4.1 \mathrm{ab}$ \\
\hline 9306 & 22 & 0 & $2.5 \pm 2.5 \mathrm{a}$ & $92.5 \pm 3.8^{y} \mathrm{a}$ \\
\hline \multirow[t]{2}{*}{8877} & 22 & 0 & $0 \mathrm{a}$ & $87.5 \pm 4.2 \mathrm{a}$ \\
\hline & 4 & 0 & $5.0 \pm 3.3 \mathrm{a}$ & $92.5 \pm 3.8^{\mathrm{y}} \mathrm{a}$ \\
\hline
\end{tabular}

${ }^{\mathrm{z}}$ Means followed by different letters in each column are significantly different at the 0.05 level. Data are means of 10 replicates and four samples per replicate.

${ }^{\mathrm{y}}$ Means followed by the different letters in each column are significantly different at 0.01 levels. 


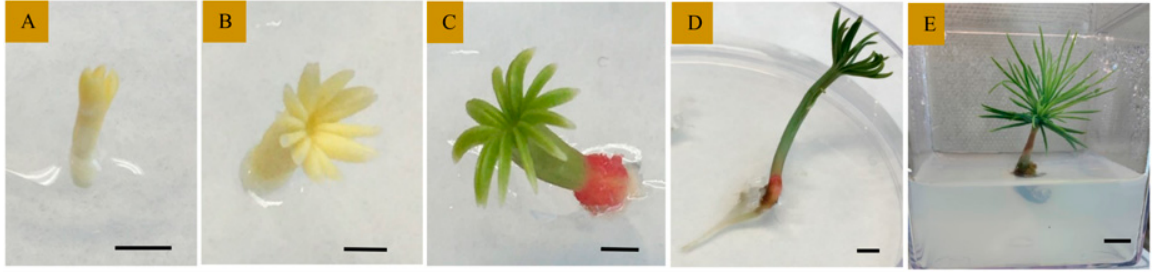

Fig. 3. A naked embryo germination process in vitro of sugar pine. (A) An embryo on germination medium at day 0 . (B) The embryonic axis elongation and the cotyledon expansion at $\approx 3 \mathrm{~d}$. (C) A germinating embryo turned green after $\approx 1$ week in culture. (D) A fully developed seedling after $\approx 4$ weeks in culture. (E) Shoot multiplication within $\approx 8$ weeks in culture. Bars $=5 \mathrm{~mm}$.

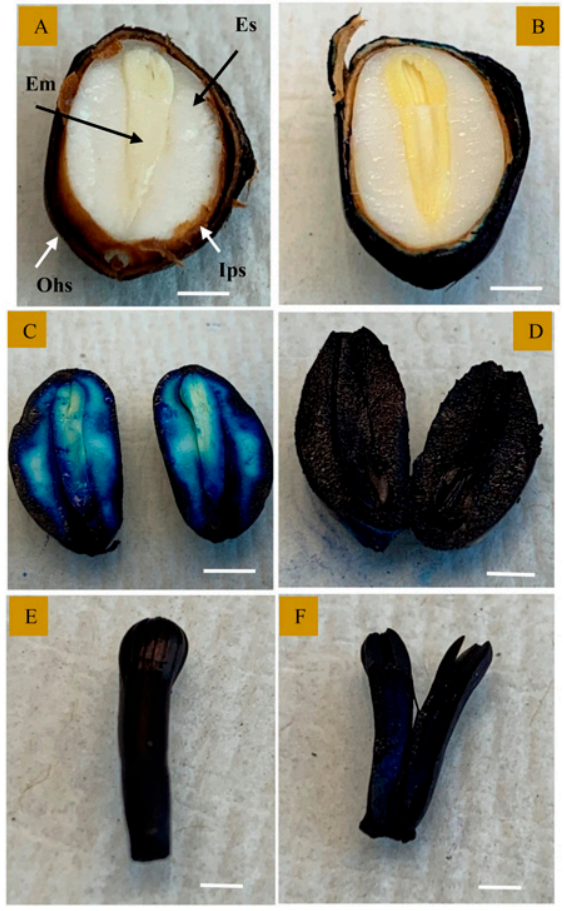

Fig. 4. Water permeability test of sugar pine seeds. (A) Intact seeds immersed in water for $7 \mathrm{~d}$ used as the control. (B) Intact seeds immersed in 1\% methylene blue for $7 \mathrm{~d}$ showing no staining of endosperm and embryo. (C) Hulled seeds were immersed in $1 \%$ methylene blue for $1 \mathrm{~d}$, exhibiting partial staining. (D) Complete staining of hulled seeds after $2 \mathrm{~d}$. (E) A naked embryo was immersed in 1\% methylene blue for $1 \mathrm{~h}$. (F) A naked embryo was immersed in $1 \%$ methylene blue for $1 \mathrm{~h}$. The embryo was cut longitudinally, showing completely staining inside. Ohs $=$ outer hard seed coat; Ips = inner papery seed coat; Es = endosperm; Em = embryo. Bars $=2 \mathrm{~mm}$.
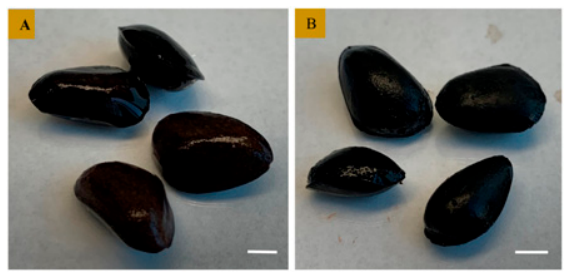

Fig. 5. Chemical scarification of intact sugar pine seeds. (A) Intact seeds soaked in $5 \mathrm{M} \mathrm{HCl}$ for $4 \mathrm{~h}$. Seed coat could not be softened or ruptured. (B) Intact seeds soaked in $5 \mathrm{~m} \mathrm{NaOH}$ for $4 \mathrm{~h}$. Seed coat could not be softened or ruptured. Bars $=2 \mathrm{~mm}$. mechanical restriction, allow water imbibition and air exchange for embryo growth. Artificial opening failed to improve germination. When these seeds were cultured on germination medium, extremely low germination $(\leq 5 \%)$ was observed with both longitudinally and horizontally cut hulled seeds (Table 4). Hulled seeds either showed no germination (Fig. 6A) or exhibited abnormal germination with distorted fascicles (needles) or no elongation of stems (Fig. 6B). These results indicate that other mechanism(s) such as inhibitors may be present in the endosperm interfered with seed germination.

\section{Discussion}

The ultimate objective of this study was to establish a reliable and efficient seed germination method to continuously provide uniform plant materials for tissue culture and genetic transformation in sugar pine. To achieve this goal, effects of various factors including seed type, cold stratification, chemical scarification, $\mathrm{GA}_{3}$ treatment, and artificial opening were investigated.

There was significant variation in average weight of seeds among the three sugar pine genotypes in this study; however, this variation was not a contributing factor to seed germination performance. The heavier and larger seeds of 9375 and 9306 did not result in any higher germination regardless of using intact seeds, hulled seeds, and naked embryos. Larger seeds may contain a larger endosperm and embryo, which give them the advantage of germination; however, under in vitro culture condition, seeds/embryos can absorb sufficient nutrients from culture medium to germinate. This is one reason the size and weight of seeds did not affect germination in this study.

Intact seeds of all three genotypes failed to germinate (Table 2). The causes of the lack of germination for intact seeds were examined. We found that the seedcoat of sugar pine was hard and difficult to rupture. The seedcoat could not be softened by $5 \mathrm{M} \mathrm{HCl}$ and $5 \mathrm{~m} \mathrm{NaOH}$ soaking (Fig. 5). The hard seedcoat acted as a mechanical barrier for tissue expansion. Methylene blue test proved that the seedcoat of sugar pine was waterimpermeable, which prevents water imbibition. The ability of a seed to take up water was a prerequisite for seed germination. Our study showed that nonliving double layers of seedcoat undoubtedly played at least a dual role in limiting germination by preventing the absorption of water and exercising mechanical restriction to the expansion of the embryo; therefore, no germination could occur with intact seeds. In this sense, sugar pine seeds had physical dormancy imposed by the seedcoat. In the current study, we encountered contamination with intact seeds cultured in vitro, but no contamination was observed with hulled seeds and naked embryo culture. This suggested that certain pathogenic agents were contained in the double-layered seedcoat. It is unclear whether the seedcoat of sugar pine also contained inhibiting substances that further prevented germination. Seed coat restricting seed germination through various mechanisms has also been found in other Pinus species (Barnett, 1972, 1976, 1997; Berlyn, 1967; Cooke et al., 2002; Li et al., 1989; Murphy and Thomas, 1981; Wang et al., 2000).

The role of endosperm in seed germination has not yet been fully investigated in sugar pine. As a gymnosperm, the endosperm of sugar pine is haploid female gametophyte tissue and does not result from a fusion of nuclei, as is the case in angiosperm; however, they are functionally analogous (Stanley, 1957). In the present study, hulled seeds exhibited extremely low germination $(\leq 5 \%)$ with abnormal seedling growth (Table 2, Fig. 6C). Endosperm proved to be water permeable, thus absorption of water occurred. Artificial opening of the endosperm that removed mechanical restraint and allowed air exchange did not improve germination (Table 4). Our findings support the hypothesis that certain inhibitors are present in the endosperm that interfere with seed germination. Corvillon and MartinezHonduvilla (1980) reported that several inhibitors in the endosperm of Pinus pinea $\mathrm{L}$. were involved in the regulation of seed germination. Therefore, the embryo might be dormant when the endosperm was present.

Consistent high germination, from $70 \%$ to $95 \%$, could be obtained with both coldstratified and nonstratified seeds when naked embryos were isolated and cultured on medium (Table 2). This indicates that embryos are capable of germination and do not have any kind of dormancy. Sugar pine seeds contain fully developed embryos, although they may differ at the developmental stage (Fig. 2B). These embryos could germinate and develop into normal plants when cultured on medium. Naked embryos germinated rapidly (Fig. 3). A sign of germination could be seen at as early as $3 \mathrm{~d}$, and germinating seedlings could be used as plant materials for tissue culture and genetic transformation after $\approx 2$ weeks in culture. In contrast, hulled seeds required at least 10 to 12 weeks for germination to occur with an extremely low rate and abnormal seedling growth (Fig. 6). Intact seeds did not show any germination even after 12 weeks. Seed population was mixed and, except for fully developed healthy seeds, also included undeveloped, 
pathogen-infected and insect-damaged seeds. These seeds were unlikely to germinate. Embryo culture provided another advantage that only healthy fully developed embryos were cultured by dissecting seeds, and this was attributed for high germination of embryo culture as well. The present study demonstrated that embryo culture could be used as a reliable and efficient method to generate uniformed plant materials in a relatively fast fashion.

$\mathrm{GA}_{3}$ is commonly used to break seed dormancy and promote seed germination (Leadem, 1987; Sharma et al., 2020; Zhao and Jiang, 2014). Unfortunately, the inclusion of $\mathrm{GA}_{3}$ at $1 \mathrm{mg} \cdot \mathrm{L}^{-1}$ in the germination medium failed to improve seed germination in the present study (Table 3). This is consistent with observations made by Pitel and Wang (1989) that treatment with $\mathrm{GA}_{3}$ was not effective in improving seed germination in whitebark pine (Pinus albicaulis Engelm).

Table 3. Effect of gibberellic acid $\left(\mathrm{GA}_{3}\right)$ on in vitro germination of hulled seeds of three sugar pine genotypes.

\begin{tabular}{lcc}
\hline Variety & $\mathrm{GA}_{3}(\mathrm{mg} / \mathrm{L})$ & Germination $(\%)^{\mathrm{z}}$ \\
\hline 9375 & 0 & $0 \mathrm{a}$ \\
& 1 & $0 \mathrm{a}$ \\
9306 & 0 & $2.5 \pm 2.5 \mathrm{a}$ \\
& 1 & $5.0 \pm 3.3 \mathrm{a}$ \\
8877 & 0 & $2.5 \pm 2.5 \mathrm{a}$ \\
& 1 & $0 \mathrm{a}$ \\
\hline
\end{tabular}

$\overline{{ }^{z} \text { Means followed by the same letter in each column }}$ are not significantly different at the 0.05 level. Data are means of 10 replicates and four samples per replicate.

Table 4. Effect of artificial opening on in vitro germination of hulled seeds of three sugar pine genotypes.

\begin{tabular}{llc}
\hline Variety & \multicolumn{1}{c}{ Treatment } & Germination $(\%)^{\mathrm{z}}$ \\
\hline 9375 & Control & $0 \mathrm{a}$ \\
& Longitudinal cut & $2.5 \pm 2.5 \mathrm{a}$ \\
& Horizontal cut & $5.0 \pm 3.3 \mathrm{a}$ \\
& & \\
9306 & Control & $2.5 \pm 2.5 \mathrm{a}$ \\
& Longitudinal cut & $0 \mathrm{a}$ \\
& Horizontal cut & $2.5 \pm 2.5 \mathrm{a}$ \\
8877 & Control & $0 \mathrm{a}$ \\
& Longitudinal cut & $0 \mathrm{a}$ \\
& Horizontal cut & $5.0 \pm 3.3 \mathrm{a}$ \\
\hline
\end{tabular}

${ }^{\mathrm{z}}$ Means followed by the same letter in each column are not significantly different at the 0.05 level. Data are means of 10 replicates and four samples per replicate.
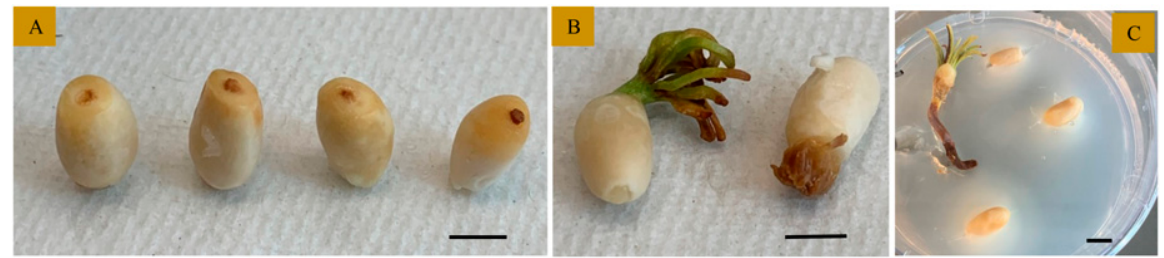

Fig. 6. Germination process of hulled sugar pine seeds. (A) Hulled seeds horizontally cut at both ends showed no germination. (B) Hulled seeds horizontally cut at both ends exhibited abnormal germination with distorted fascicles (needles) or no elongation of stems. (C). Hulled seeds on germination medium showed abnormal growth. Photos were taken after 12 weeks in culture. Bars $=5 \mathrm{~mm}$. method would not be feasible because rapid and uniform germination is the key for successful propagation. Among limited literature on sugar pine seed germination, a vast majority focused on intact seeds planted in soils. To our knowledge, there is no publication on germination of the three types of sugar pine seeds in this study in vitro. The information provided here will be beneficial for related studies.

\section{Conclusions}

A feasible and efficient germination method for sugar pine was established in this study. Isolated naked embryos germinated rapidly and uniformly with high germination rate among all three genotypes, and can be used for tissue culture and genetic transformation in sugar pine. Intact seeds failed to germinate, and hulled seeds germinated at an extremely low rate. Cold stratification, chemical stratification, $\mathrm{GA}_{3}$ treatment, and artificial openings failed to improve germination of intact seeds and hulled seeds. This study showed that naked embryos of sugar pine were not dormant, and germination inhibition was mainly induced by the enclosing structures of embryos, including mechanical barrier and water-impermeability by hard seedcoat and inhibitory endosperm.

\section{Literature Cited}

Ahlstrom, G. 1992. Inventory trends and values of sugar pine, p. 22-27. In: B.B. Kinloch, Jr., M. Marosy, and M.E. Huddleston (eds.). Sugar pine: Status, values, and roles in ecosystems. Proceedings of a Symposium Presented by the California Sugar Pine Management Committee, 30 Mar.-1 Apr. 1992, Univ. California, Davis.

Allen, G.S. 1960. Factors affecting the viability and germination behavior of coniferous seeds. IV. Stratification period and incubation temperature, Pseudotsuga menziesii (Mirb.). Franco. For. Chron. 36:18-29.

Barnett, J.P. 1972. Seed coat influences dormancy of loblolly pine seeds. Can. J. For. Res. 2(1):710, doi: 10.1139/x72-002.

Barnett, J.P. 1976. Delayed germination of southern pine seeds related to seed coat constraint. Can. J. For. Res. 6(4):504-510.

Barnett, J.P. 1997. Relating pine seed coat characteristics to speed of germination, geographic variation, and seedling development. Tree Planter's Notes 48(1/2):38-42.

Baron, F.J. 1978. Moisture and temperature in relation to seed structure and germination of sugar pine (Pinus lambertiana Dougl.). Amer. J. Bot. 65:804-810.

Berlyn, G.R. 1967. The structure of germination in Pinus lambertiana Dougl. Yale School of Forestry \& Environmental Studies, Bulletin Series, 77.

Bewley, J.D. 1997. Seed germination and dormancy. Plant Cell 9:1055-1066, doi: 10.1105/ tpc.9.7.1055.

Carpita, N.C., A. Skaria, J.P. Barnett, and J.R. Dunlap. 1983. Cold stratification and growth of radicles of loblolly pine (Pinus taeda) embryos. Physiol. Plant. 59(4):601-606, doi: 10.1111/ j.1399-3054.1983.tb06287.x

Cermak, R.W. 1992. Sugar pine in the history of the west coast, p. 10-21. In: B.B. Kinloch, Jr., 
M. Marosy, and M.E. Huddleston (eds.). Sugar pine: Status, values, and roles in ecosystems. Proceedings of a Symposium Presented by the California Sugar Pine Management Committee, 30 Mar.-1 Apr. 1992, Univ. California, Davis.

Cooke, J., B. Cooke, and D. Gifford. 2002. Loblolly pine seed dormancy: Constraints to germination. New For. 23:239-256, doi: 10.1023/ A:1020306816009.

Corvillon, E. and C.J. Martinez-Honduvilla. 1980. Germination inhibitors in embryos and endosperms from Pinus pinea seeds. Ital. J. Biochem. 29(6):405-411.

Devey, M.E., A. Delfino-Mixt, B.B. Kinloch, Jr., and D.B. Nealet. 1995. Random amplified polymorphic DNA markers tightly linked to a gene for resistance to white pine blister rust in sugar pine. Proc. Natl. Acad. Sci. USA 92:2066-2070, doi: 10.1073/pnas.92.6.2066.

Donald, D.G.M. 1987. The effect of long term stratification on the germination of Pinus pinaster Ait. South. Afr. For. J. 143:25-29, doi: 10.1080/00382167.1987.9630297.

Dong, L., C. Shao, and Z. Zhang. 2002. Characteristics of embryo dormancy and germination of Pinus bungeana. Scientia Silvae Sinicae 39(6):47-54.

Fernando, D.D., S.M. Long, and R.A. Sniezko. 2005. Sexual reproduction and crossing barriers in white pines: The case between Pinus lambertiana (sugar pine) and $P$. monticola (western white pine). Tree Genet. Genomes 1:143-150, doi: 10.1007/s11295-005-0015-z.

Ferrell, G.T. and R.F. Scharpf. 1992. Endemic insect pests and diseases of sugar pine, p. 3437. In: B.B. Kinloch, Jr., M. Marosy, and M.E. Huddleston (eds.). Sugar pine: Status, values, and roles in ecosystems. Proceedings of a Symposium Presented by the California Sugar Pine Management Committee, 30 Mar.-1 Apr. 1992, Univ. California, Davis.

Feurtado, J.A., S.J. Ambrose, A.J. Cutler, A.R.S. Ross, and S.R. Abrams. 2004. Dormancy termination of western white pine (Pinus monticola Dougl. Ex D. Don) seeds is associated with changes in abscisic acid metabolism. Planta 218:630-639, doi: 10.1007/s00425-003-11398 .

Ghildiyal, S.K., C.M. Sharma, and S. Gairola. 2009. Effect of cold stratification on the germination of seeds of chirpine (Pinus roxburghii Sargent) from Indian Himalayan region. Nat. Sci. Sleep 7(8):36-43.

Kabar, K. 1998. Comparative effects of kinetin, benzyladenine and gibberellic acid on abscisic acid inhibited seed germination and seedling growth of red pine and arbor vitae. Turk. J. Bot. 22:1-6.

Kinloch, B.B., Jr., and W.H. Scheuner. 1990. Pinus lambrtiana Dougl. Sugar pine-Pinaceae pine family, p. 370-379. In: R.M. Burn and B.H. Honkala (eds.). Silvics of North America. Vol. 1: Conifers. Agriculture Handbook 654, USDA Forest Service, Washington, DC.

Krugman, S.L. 1966. Artificial ripening of sugar pine seeds. U.S. Forest Service Research Paper
PSW-32. Pacific SW Forest \& Range Experiment Station, Berkeley, CA.

Kucera, B., M.A. Cohn, and G. Leubner-Metzget. 2005. Plant hormone interactions during seed dormancy release and germination. Seed Sci. Res. 15:281-307, doi: 10.1079/SSR2005218.

Kumar, R., G.S. Shamet, H. Mehta, N.M. Alam, J.M.S. Tomar, O.P. Chturvedi, and N. Khajuria. 2014. Influence of gibberellic acid and temperature on seed germination in Chilgoza pine (Pinus gerardiana Wall.). Indian J. Plant. Physiol. 19:363-367, doi: 10.1007/s40502014-0119-2.

Lavania, S.K., R.P. Singh, and V. Singh. 2006. Effect of gibberellic acid and $\mathrm{pH}$ on seed germination in blue pine (Pinus wallichiana). Indian For. 132(8):1024-1028.

Leadem, C.L. 1987. The role of plant growth regulators in the germination of forest tree seeds. Plant Growth Regulat. 6:61-93.

Li, L., G.H. Zheng, and H.W. Xing. 1989. Relationship between seedcoat of Korean pine and its dormancy. Acta Bot. Sin. 31(12):928-933.

Malabadi, B.R. and K. Nataraja. 2017. Genetic transformation of conifers: Applications in and impact on commercial forestry. Transgenic Plant J. 1(2):289-313.

Maloney, P.E., D.R. Vogler, A.J. Eckert, C.E. Jensen, and D.B. Neale. 2011. Population biology of sugar pine (Pinus lambertiana Dougl.) with reference to historical disturbances in the Lake Tahoe Basin: Implications for restoration. For. Ecol. Mgt. 262(5):770-779, doi: 10.1016/ j.foreco.2011.05.011.

Maleki, S.S., K. Mohammadi, and K.S. Ji. 2018. Study on factors influencing transformation efficiency in Pinus massoniana using Agrobacterium tumefaciens. Plant Cell Tissue Organ Cult. 133:437-445, doi: 10.1007/s11240018-1388-7.

Malik, A.R. and G.S. Shamet. 2008. Germination and biochemical changes in the seeds of chilgoza pine (Pinus gerardiana Wall.) by stratification: An endangered conifer species of the north-west Himalaya. Indian J. Plant. Physiol. 13:278-283.

Malik, A.R., G.S. Shamet, and A. Majid. 2008 Seed stratification of Pinus gerardiana Wall: Effect of stratification duration and temperature. Indian For. 134:1072-1078.

Marti, A.F. and R.S. Dodd. 2018. Using CRISPR as a gene editing tool for validating adaptive gene function in tree landscape genomics. Front. Ecol. Evol. 6:1-6, doi: 10.3389/fevo. 2018.00076.

McLemore, B.F. and F.J. Czabator. 1961. Length of stratification and germination of loblolly pine seed. J. For. 59:266-269.

Murashige, T. and F. Skoog. 1962. A revised medium for rapid growth and bioassay with tobacco tissue culture. Physiol. Plant. 15:473495.

Murphy, M.B. and N.L. Thomas. 1981. Changes in phenolic acids and abscisic acid in sugar pine seed coats during stratification. Physiol. Plant. 52(3):370-374, doi: 10.1111/j.13993054.1981.tb06056.x.
Nelson, S.O. 2015. Seed treatment application. Dielectric properties of agricultural materials and their applications. Academic Press, Elsevier Inc., Cambridge, MA.

Pitel, J.A. and B.S.P. Wang. 1989. Physical and chemical treatment to improve germination of whitebark pine seeds. Proceedings of Symposium on Whitebark Pine Ecosystems: Ecology and Management of a High Mountain Resource, 29-31 Mar. 1989, Bozeman, Montana. 270:130-133.

Schubert, G.H. 1955. Effect of storage temperature on viability of sugar, jeffrey, and ponderosa pine seed, p. 1-6. Research Note 100. U.S. Department of Agriculture, Forest Service, California Forest and Range Experiment Station, Berkeley, CA.

Sharma, L., B.M. Reddy, M. Chatterjee, S. Dhawan, and V. Pa. 2020. Influence of mechanical scarification and gibberellic acid on seed germination and seedling performance in Pinus gerardiana Wall. Intl. J. Curr. Microbiol. Appl. Sci. 9(4):1356-1365, doi: 10.20546/ijcmas.2020. 904.161 .

Shu, K., W. Zhou, F. Chen, X. Luo, and W. Yang. 2018. Abscisic acid and gibberellins antagonistically mediate plant development and abiotic stress responses. Front. Plant Sci. 9:1-8, doi: 10.3389/fpls.2018. 00416.

Skordilis, A. and C.A. Thanos. 1995. Seed stratification and germination strategy in the Mediterranean pines (Pinus brutia and Pinus halepensis). Seed Sci. Res. 5:151-160, doi: 10.1017/S0960258500002774.

Song, Y., J. Zhu, Q. Yan, and G. Wang. 2018. Korean pine seed: Linking changes in dormancy to germination in the 2 years following dispersal. Forestry 91(1):98-109, doi: 10.1093/ forestry/cpx037.

Stanley, R.G. 1957. Krebs cycle activity of mitochondria from endosperm of sugar pine seed (Pinus lambertiana Dougl.). Plant Physiol. 32(5):409-412.

Stone, E.C. 1957. Embryo dormancy and embryo vigor of sugar pine ( $P$. lambertiana) as affected by length of storage and storage temperatures. For. Sci. 3(4):357-371.

Tanaka, Y. 1984. Assuring seed quality for seedling production: Cone collection and seed processing, testing, storage, and stratification, p. 27-39. In: M.L. Duryea and D.L. Thomas (eds.). Forestry Nursery Manual: Production of Barefoot seedlings. The Hague/Boston/Lancaster for Forest Research Laboratory, Oregon State University.

Wang, X., J. Liu, and J. Wang. 2000. Variation of dormancy characteristic of different Pinus bungeana seed sources. Chinese J. Appl. Ecol. 11:9-12.

Xin, Z. 2008. Seed dormancy mechanism of six pine species. J. SW. For. Coll. 28:5-9.

Zhao, G. and X. Jiang. 2014. Role of gibberellin and auxin in promoting seed germination and seedlings vigor in Pinus massoniana. For. Sci. 60(2):367-373, doi: 10.5849/forsci.12143. 